\title{
Pengaruh Kejelasan Sasaran Anggaran, Kompetensi Aparatur Desa, dan Kepemimpinan Pada Akuntabilitas Pengelolaan Dana Desa
}

\author{
Ida Bagus Pramayoga ${ }^{1}$ \\ Fakultas Ekonomi dan Bisnis \\ Universitas Udayana, Indonesia \\ Email: gus_prama@rocketmail.com
}

\author{
I Wayan Ramantha ${ }^{2}$ \\ Fakultas Ekonomi dan Bisnis \\ Universitas Udayana, Indonesia
}

\begin{abstract}
ABSTRAK
Yang melatar belakangi penelitian ini adalah adanya temuantemuan terkait penyalahgunaan dan pengelolaan dana desa di Kecamatan Gianyar. Penelitian ini memiliki tujuan untuk mengetahui pengaruh dari kejelasan sasaran anggaran, kompetensi aparatur desa, serta kepemimpinan pada akuntabilitas pengelolaan dana desa di Kecamatan Gianyar. Metode pengumpulan sampel yang digunakan adalah kuesioner dan dianalisis menggunakan analisis Regresi Linier Berganda. Berdasarkan hasil analisis yang telah dilakukan, dapat disimpulkan bahwa kejelasan sasaran anggaran, kompetensi aparatur desa, dan kepemimpinan berpengaruh positif pada akuntabilitas pengelolaan dana desa yang berarti semakin meningkat kejelasan dari sasaran anggaran, kompetensi dari aparatur desa, serta kepemimpinan dari pemimpin terkait maka semakin baik pula akuntabilitas dari pengelolaan dana desa di Kecamatan Gianyar.
\end{abstract}

Kata Kunci: Kejelasan Sasaran Anggaran; Kompetensi Aparatur Desa; Kepemimpinan; Akuntabilitas.

Effect of Clarity of Budget Targets, Apparatus Competencies, and Leadership on Village Fund Management Accountability

\begin{abstract}
Underlying this research are findings related to misuse and management of village funds in Gianyar District. This study aims to determine the effect of clarity of budget targets, competence of village officials, and leadership on accountability of village fund management in Gianyar District. The sample collection method used was a questionnaire and analyzed using Multiple Linear Regression analysis. Based on the results of the analysis conducted, it can be concluded that the clarity of the budget targets, the competence of the village apparatus, and leadership has a positive effect on the accountability of village fund management, which means that the clarity of the budget targets, the competence of the village apparatus, and the leadership of the related leaders are better. accountability of the management of village funds in the District of Gianyar.
\end{abstract}

Keywords: Clarity Of Budget Targets; Village Apparatus Competencies; Leadership; Accountability.

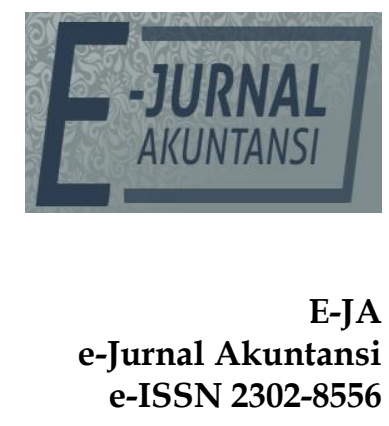

Vol. 30 No. 1

Denpasar, Januari 2020

Hal. 226-237

Artikel Masuk: 5 November 2019

Tanggal Diterima: 30 Desember 2019 


\section{PENDAHULUAN}

Desa tidak lagi menjadi objek pembangunan, melainkan telah menjadi subjek dan ujung tombak pembangunan dan peningkatan kesejahteraan masyarakat. Berdasarkan Peraturan Menteri Desa No. 2 Tahun 2015 tentang Pedoman Musyawarah Desa, musyawarah desa diselenggarakan paling lambat satu kali dalam 1 (satu) tahun atau sesuai kebutuhan dan diikuti oleh Pemerintah Desa, Badan Persyaratan Desa, dan unsur masyarakat. Salah satu hasil dari musyawarah desa adalah Rencana Kerja Pemerintah Desa (RKPDes) yang pendanaannya bersumber dari APBDes. APBDes berisi pendapatan, belanja desa dan pembiayaan.

Pada tahun 2019 pemerintah mengalokasikan dana desa sebesar Rp70 triliun dengan alokasi dasar sebesar Rp672.421.000,00. Provinsi Bali pada tahun 2019 menerima pengalokasian dana desa sebesar Rp518.189.586.000,00. Kabupaten Gianyar merupakan penerima alokasi dana desa terbesar kelima di Bali setelah Kabupaten Bangli yaitu sebesar Rp59.992.299.000,00. Kabupaten Gianyar memiliki 7 kecamatan dengan jumlah desa keseluruhan sebanyak 64 desa. Besar kecilnya dana yang dialokasikan ketiap desa di seluruh Indonesia berbeda-beda, salah satu penyebabnya adalah jumlah wilayah desa serta tingkat angka kemiskinan di desa terkait (Kementrian Keuangan, 2017). Kecamatan Gianyar merupakan penerima alokasi dana desa terbesar di Kabupaten Gianyar yaitu sebesar Rp11.023.918.000,00. Dana desa yang diterima oleh Kecamatan Gianyar pada tahun 2019 dapat dilihat dalam Tabel 1.

Tabel 1. Rincian Dana Kecamatan Gianyar Menurut Desa T.A 2019 (dalam rupiah)

\begin{tabular}{lll}
\hline No & Nama Kecamatan & Jumlah Alokasi Dana Desa \\
\hline 1 & Desa Tulikup & 899.316 .000 \\
2 & Desa Sidan & 841.316 .000 \\
3 & Desa Lebih & 824.392 .000 \\
4 & Desa Babakan & 885.165 .000 \\
5 & Desa Siangan & 872.434 .000 \\
6 & Desa Suwat & 1.777 .386 .000 \\
7 & Desa Petak & 817.593 .000 \\
8 & Desa Serongga & 836.170 .000 \\
9 & Desa Petak Kaja & 828.172 .000 \\
10 & Desa Temesi & 794.828 .000 \\
11 & Desa Sumita & 838.299 .000 \\
12 & Desa Tegal Tugu & 808.935 .000 \\
Total & & 11.023 .918 .000 \\
\hline
\end{tabular}

Sumber: Data Penelitian, 2019

Dana desa yang sangat besar ini mulai membuat kekhawatiran mengenai kesiapan desa dan mengelola dana desa yang telah dialokasikan. Kekhawatiran ini terbukti dengan adanya temuan terkait dengan dana desa yang digunakan untuk memperbaiki kantor desa, masalahnya terletak pada dana desa tidak boleh dipergunakan untuk pembangunan kantor desa, dana desa hanya diperuntukkan untuk kepentingan masyarakat desa. Pembangunan kantor desa 
tersebut juga menggunakan dana dari sumber lain sehingga laporan pertanggungjawaban yang dipertanggung jawabkan menjadi fiktif, menjadi fiktif karena satu bukti transaksi digunakan pada dua laporan pertanggung jawaban yang berbeda. Kasus lain yang ditemukan oleh pihak Inspektorat Kabupaten Gianyar adalah adanya dana desa yang digunakan membiayai pendidikan lima belas orang untuk melanjutkan pendidikan ke jenjang Strata 1 (S1), sedangkan dana desa hanya boleh digunakan untuk jenjang pendidikan Taman KanakKanak (TK) dan Sekolah Dasar (SD) sedangkan untuk jenjang sembilan tahun selanjutnya menjadi wewenang kabupaten dan provinsi. Terdapat juga temuan mengenai dana desa yang digunakan untuk suatu kelompok masyarakat tetapi dana desa disimpan di rekening pribadi istri perbekel desa, seharusnya dana tersebut ditransfer ke rekening atas nama kelompok terkait yang akan diberikan bantuan dana, kesalahan prosedur tersebut berpotensi menimbulkan tindak korupsi dan terdapat temuan lainnya dimana dana desa digunakan untuk memperbaiki jalan yang merupakan kewenangan kabupaten. Maka dari itu agar pengelolaan keuangan desa dapat menyejahterakan masyarakat desa, maka idealnya harus dikelola berdasarkan prinsip-prinsip good governance yang salah satunya adalah akuntabilitas (Hanafie et al, 2019).

Untuk memenuhi akuntabilitas perlu diperhatikan beberapa hal diantaranya adalah anggaran, pengendalian internal, dan sistem pelaporan (Artha \& Rasmini, 2019). Anggaran adalah rencana yang disajikan dalam bentuk kuantitatif serta berjangka waktu. Hal penting dalam penganggaran yang harus di perhatikan adalah ketepatan atau kejelasan sasaran dari anggaran tersebut. Dengan sasaran yang jelas atau tepat, target-target atau rencana yang disusun dapat memiliki nilai manfaat sesuai dengan yang diinginkan.

Menurut Indonesia Coruption Watch (ICW) menyatakan terdapat empat faktor utama penyebab penyelewengan penggunaan dana desa yang salah satunya adalah kurangnya kompetensi dari aparatur desa sebagai pihak yang mengelola dana desa (www.tribunnews.com). Kualitas dari Sumber Daya Manusia (SDM) merupakan faktor yang sangat menentukan keberhasilan suatu organisasi atau lembaga pemerintahan, oleh karena itu kompetensi aparatur desa sangat penting dikarenakan aparatur desa yang akan mengelola dana desa tersebut. Maka dari itu kompetensi perangkat desa juga menjadi sangat dibutuhkan untuk mencapai akuntabilitas. Kepemimpinan yang berjalan dalam organisasi menentukan sukses atau tidaknya organisasi (Eka et al, 2015).

Kejelasan sasaran anggaran merupakan seberapa jauh sasaran anggaran ditetapkan secara jelas dan spesifik yang bertujuan agar anggaran tersebut dapat dimengerti oleh orang yang bertanggungjawab. Penelitian sebelumnya yang dilakukan oleh Hidayat (2015), Ali (2015) serta Judarmita \& Supadmi (2017) menyimpulkan bahwa jelasnya sasaran dari anggaran memilik pengaruh positif terbadap akuntabilitas pengelolaan dari dana desa. Dari apa yang telah diuraikan tersebut, dapat dirumuskan hipotesis sebagai berikut :

$\mathrm{H}_{1}$ : Kejelasan sasaran anggaran berpengaruh positif pada akuntabilitas pengelolaan dana desa.

Tingkat kompetensi dari perangkat desa akan berdampak pada kinerja dari perangkat desa (Kolibácová, 2014). Pengelolaan dana desa kerap menemui banyak hambatan dalam pelaksananya, salah satunya dari faktor sumber daya 
manusia (SDM). Penelitian yang sebelumnya dilakukan oleh Mahayani (2017) serta Julia \& Gayatri (2019) menyimpulkan kompetensi perangkat desa memiliki pengaruh secara positif terhadap akuntabilitas pengelolaan dari dana desa. Berdasarkan dari apa yang telah diuraikan tersebut, dapat dirumuskan hipotesis sebagai berikut :

$\mathrm{H}_{2}$ : Kompetensi aparatur desa berpengaruh positif pada akuntabilitas pengelolaan dana desa.

Kepala desa berperan sebagai pemimpin yang menjadi pengambil keputusan dan bertindak sebagai penggerak bawahannya untuk mencapai tujuan organisasi yang salah satunya adalah kesejahteraan masyarakat desa, maka dari itu kepemimpinan dari kepala desa akan menjadi sangat berpengaruh dalam menjalankan organisasi. Sebelumnya telah dilakukan penelitian oleh Bagus et al (2013), Ratu (2017), serta Julia \& Gayatri (2019) yang menyimpulkan bahwa kepemimpinan berpengaruh secara positif terhadap akuntabilitas pengelolaan dana desa. Berdasarkan dari apa yang telah diuraikan tersebut, dapat dirumuskan hipotesis sebagai berikut :

$\mathrm{H}_{3}$ : Kepemimpinan berpengaruh positif pada akuntabilitas pengelolaan dana desa.

\section{METODE PENELITIAN}

Populasi dari penelitian ini adalah seluruh perangkat desa dan pihak yang terlibat pada musyawarah desa yang berada di seluruh desa se-Kecamatan Gianyar yaitu sebanyak 120 responden yang tiap-tiap desanya diambil 10 responden. Metode pengumpulan sampel yang digunakan adalah purposive sampling. Dari 120 responden yang diberikan, seluruhnya digunakan sebagai sampel karena seluruhnya memenuhi kriteria sebagai sampel. Data didapatkan dengan menyebarkan angket/kuesioner dengan skala likert 5 kepada responden di tiap desa.

Pengujian yang dilakukan dalam penelitian ini adalah uji validitas, uji reliabilitas, uji asumsi klasik, uji kelayakan model, uji koefisien determinasi, uji statistik $\mathrm{t}$ dan untuk menganalisis hipotesis dalam penelitian ini, metode analisis yang digunakan adalah Analisis Regresi Linier Berganda yang dibantu program SPSS dengan persamaan yang dirumuskan adalah sebagai berikut :

$Y=\alpha+\beta_{1} X_{1}+\beta_{2} X_{2}+\beta_{3} X_{3}+\varepsilon$

\section{HASIL DAN PEMBAHASAN}

Pengujian yang pertama yang dilakukan dalam penelitian ini adalah uji validitas. Hasil uji menunjukkan bahwa keseluruhan indikator yang digunakan memiliki koefisien korelasi lebih besar dari 0,3 sehingga instrumen-instrumen pada setiap variabel penelitian dinyatakan valid.

Setelah dilakukan uji validitas selanjutnya adalah uji reliabilitas yang digunakan untuk memenuhi ketepatan jawaban kuesioner pada suatu periode dengan periode lainnya. Hasil uji reliabilitas dapat dilihat pada Tabel 2. 
Tabel 2. Hasil Uji Reliabilitas

\begin{tabular}{lll}
\hline Variabel & Cronbach' Alpha & Keterangan \\
\hline Kejelasan Sasaran Anggaran $\left(\mathrm{X}_{1}\right)$ & 0.805 & Reliabel \\
Kompetensi Aparatur $\left(\mathrm{X}_{2}\right)$ & 0.828 & Reliabel \\
Kepemimpinan $\left(\mathrm{X}_{3}\right)$ & 0.857 & Reliabel \\
Akuntabilitas Pengelolaan Dana Desa $(\mathrm{Y})$ & 0.812 & Reliabel \\
\hline
\end{tabular}

Sumber: Data Penelitian, 2019

Berdasarkan hasil uji reliabilitas, seluruh instrumen yang digunakan di tiap variabel dinyatakan reliabel Karen nilai cronbach' alpha lebih besar dari 0,6.

Statistik deskriptif dalam penelitian ini digunakan untuk memberikan informasi mengenai karakteristik variabel-variabel penelitian. Hasil uji statistik deskriptif dapat dilihat pada Tabel 3.

Tabel 3. Hasil Uji Statistik Deskriptif

\begin{tabular}{llllll}
\hline Variabel & $\mathrm{N}$ & Min & Max & Mean & $\begin{array}{l}\text { Std. } \\
\text { Deviation }\end{array}$ \\
\hline Kejelasan Sasaran Anggaran & 120 & 18.00 & 30.00 & 26.1167 & 2.33059 \\
Kompetensi Aparatur & 120 & 40.00 & 50.00 & 45.0167 & 3.18342 \\
Kepemimpinan & 120 & 35.00 & 45.00 & 39.4500 & 3.14055 \\
Akuntabilitas $\quad$ Pengelolaan & 120 & 31.00 & 40.00 & 35.1500 & 2.68093 \\
Dana Desa & & & & & \\
Valid N (listwise) & 120 & & & & \\
\hline
\end{tabular}

Sumber: Data Penelitian, 2019

Secara berurutan variabel kejelasan sasaran anggaran mempunyai nilai min, max, mean, serta deviation sebesar 18,00, 30,00, 26,1167, serta 2,33059. Secara berurutan variabel kompetensi aparatur desa mempunyai nilai min, max, mean, serta deviation sebesar 40,00, 50,00, 45,0167, serta 3,18342. Secara berurutan variabel kepemimpinan mempunyai nilai min, max, mean, serta deviation sebesar $35,00,45,00,35,1500$, serta 2,67093.

Untuk menguji apakah sampel yang digunakan telah terdistribusi normal atau belum dapat digunakan uji normalitas. Hasil uji normalitas dapat dilihat pada Tabel 4.

Tabel 4. Hasil Uji Normalitas

\begin{tabular}{ll}
\hline & Unstandardized Residual \\
\hline $\mathrm{N}$ & 120 \\
Test Statistic & 0.062 \\
Asymp.Sig (2-tailed) & 0.200
\end{tabular}

Sumber: Data Penelitian, 2019

Hasil uji menunjukkan nilai Asymp.Sig (2-tailed) diatas 5\% jadi dapat dikatakan variabelnya berdistribusi normal.

Agar kita mengetahui adanya gejala heterokedastisitas dalam model penelitian dapat dilakukan dengan menggunakan uji heterokedastisitas. Hasil dari uji heterokedastisitas dapat dilihat pada Tabel 5. 
Tabel 5. Hasil Uji Heterokedastisitas

\begin{tabular}{lll}
\hline Variabel & Corerelation Coefficient & Sig. \\
\hline Kejelasan Sasaran Anggaran & $-0,022$ & 0,813 \\
Kompetensi Aparatur Desa & $-0,144$ & 0,116 \\
Kepemimpinan & 0,117 & 0,203 \\
\hline
\end{tabular}

Sumber: Data Penelitian, 2019

Berdasarkan hasil uji heterokedastisitas yang telah dilakukan menunjukkan nilai signifikansi masing-masing variabel bebas lebih dari 0,05 sehingga disimpulkan model regresi terbebas dari heterokedastisitas.

Uji multikolinearitas bertujuan untuk membuktikan adanya hubungan linier antara variabel bebas yang satu dengan yang lainnya. Hasil dari uji multikolinearitas dapat dilihat pada Tabel 6 sebagai berikut.

Tabel 6. Hasil Uji Multikolinearitas

\begin{tabular}{lll}
\hline Variabel & Tolerance & VIF \\
\hline Kejelasan Sasaran Anggaran & 0.764 & 1.308 \\
Kompetensi Aparatur & 0.650 & 1.538 \\
Kepemimpinan & 0.607 & 1.648 \\
\hline
\end{tabular}

Sumber: Data Penelitian, 2019

Berdasarkan hasil uji multikolinearitas yang telah dilakukan menunjukkan nilai VIF dan nilai tolerance masing-masing variabel lebih kecil dari 10 dan lebih besar dari 0,10 jadi dapat dikatakan tidak ada gejala multikolinearitas.

Analisis regresi linier berganda berguna untuk mengetahui pengaruh masing-masing variabel bebas dengan variabel terikat. Hasil analisis regresi linier berganda tertera pada Tabel 7.

Tabel 7. Hasil Analisis Regresi Linier Berganda

\begin{tabular}{lllll}
\hline \multirow{2}{*}{ Variabel } & \multirow{2}{*}{ Unstandarlized Beta } & $\begin{array}{l}\text { Std. } \\
\text { Error }\end{array}$ & $\begin{array}{l}\mathrm{t} \\
\text { Hitung }\end{array}$ & $\begin{array}{l}\text { Sig. } \\
\text { Uji t }\end{array}$ \\
\hline Constant & 5,262 & 2,620 & 2,008 & 0,047 \\
Kejelasan Sasaran Anggaran & 0,518 & 0,081 & 6,400 & 0,000 \\
Kompetensi Aparatur & 0,134 & 0,064 & 2,082 & 0,040 \\
Kepemimpinan & 0,262 & 0,067 & 0,889 & 0,000 \\
\hline
\end{tabular}

Sumber: Data Penelitian, 2019

Dari hasil uji di atas maka dapat dirumuskan persamaan sebagai berikut :

$$
Y=5,262+0,518 X_{1}+0,134 X_{2}+0,262 X_{3}+e
$$

Nilai konstanta (a) 5,262 menunjukkan besarnya akuntabilitas pengelolaan dana desa adalah sebesar 5,262 apabila variabel independen bernilai konstan. Variabel kejelasan anggaran $\left(\mathrm{X}_{1}\right)$ memiliki nilai koefisien sebesar 0,518 yang berarti apabila kejelasan sasaran anggaran meningkat sebesar satu satuan maka nilai dari akuntabilitas pengelolaan dana desa (Y) akan meningkat sebesar 0,518 dengan mengasumsi variabel lain konstan. Variabel kompetensi aparatur desa $\left(X_{2}\right)$ memiliki nilai koefisien sebesar 0,134 yang berarti apabila kompetensi aparatur desa meningkat sebesar satu satuan maka nilai dari akuntabilitas pengelolaan dana desa (Y) akan meningkat sebesar 0,134 satuan dengan mengasumsi variabel lain konstan. Koefisien kepemimpinan $\left(X_{3}\right)$ memiliki nilai 
koefisien sebesar 0,262 yang berarti apabila kepemimpinan meningkat sebesar satu satuan maka nilai dari akuntabilitas pengelolaan dana desa (Y) akan meningkat sebesar 0,262 satuan dengan asumsi variabel lain konstan.

Agar dapat mengetahui apakah semua variabel bebas berpengaruh terhadap variabel terikat dapat digunakan uji kelayakan model atau uji f. Hasil dari Uji F dapat dilihat pada Tabel 8.

Tabel 8. Hasil Uji Kelayakan Model (Uji F)

\begin{tabular}{|c|c|c|c|c|c|c|}
\hline \multicolumn{2}{|c|}{ Model } & \multirow{2}{*}{$\begin{array}{l}\text { Sum of Square } \\
479,981\end{array}$} & \multirow{2}{*}{$\begin{array}{l}\mathrm{df} \\
3\end{array}$} & \multirow{2}{*}{$\begin{array}{l}\text { Mean Square } \\
159,994\end{array}$} & \multirow{2}{*}{$\begin{array}{l}\text { F } \\
49,449\end{array}$} & \multirow{2}{*}{$\begin{array}{l}\text { Sig. } \\
0,000^{b}\end{array}$} \\
\hline 1 & Regression & & & & & \\
\hline & Residual & 375,319 & 116 & 3,236 & & \\
\hline & Total & 855,300 & 119 & & & \\
\hline
\end{tabular}

Sumber: Data Penelitian, 2019

Berdasarkan hasil uji pada Tabel 8. signifikansi Uji F lebih kecil dari 0,05 yaitu 0,000 yang berarti variabel bebas berpengaruh secara serempak pada variabel terikat.

Uji koefisien determinasi $\left(\mathrm{R}^{2}\right)$ adalah untuk mengukur seberapa jauh kemampuan variansi variabel independence dalam menerangkan variansi variabel dependence. Hasil uji koefisien determinasi dapat dilihat pada Tabel 9.

Tabel 9. Hasil Uji Koefisien Determinasi $\left(\mathbf{R}^{2}\right)$

\begin{tabular}{lllll}
\hline Model & $\mathrm{R}$ & $R$ Square & Adjusted $R$ Square & Std. Error of the Estimate \\
\hline 1 & $0,749^{a}$ & 0,561 & 0,550 & 1,79875
\end{tabular}

Sumber: Data Penelitian, 2019

Dari uji yang telah di lakukan, Adjusted $R$ Square memiliki nilai sebesar 0,550 atau 55,5\% yang berarti besarnya variansi akuntabilitas pengelolaan dana desa terpengaruhi oleh kejelasan sasaran anggaran, kompetensi aparatur desa dan kepemimpinan adalah $55,5 \%$. Sisanya sebesar $45,5 \%$ dijelaskan oleh variabelvariabel lain yang tidak dijelaskan dalam penelitian ini.

Agar dapat mengetahu pengaruh semua variabel independen secara parsial digunakan uji hipotesis atau dapat disebut uji $t$. Hasil dari Uji $t$ dapat dilihat pada Tabel 10.

Tabel 10. Hasil Uji Hipotesis (Uji t)

\begin{tabular}{lll}
\hline Variabel & T Hitung & Sig. Uji t \\
\hline (Constant) & 2,008 & 0,047 \\
Kejelasan & Sasaran & 0,000 \\
Anggaran & 6,400 & \\
Kompetensi Aparatur Desa & 2,082 & 0,022 \\
Kepemimpinan & 3,889 & 0,018 \\
\hline
\end{tabular}

Sumber: Data Penelitian, 2019

Kejelasan sasaran anggaran mempunyai nilai signifikansi yang lebih kecil dari $<0,05$ dengan $\mathrm{t}$ hitung positif mengindikasikan $\mathrm{H}_{1}$ diterima. Dapat disimpulkan jelasnya sasaran dari anggaran dapat berdampak pada peningkatan akuntabilitas dari pengelolaan dana desa.

Anggaran adalah poin utama dalam upaya untuk mencapai akuntabilitas, sehingga kejelasan sasaran dari anggaran menjadi hal yang sangat penting untuk mewujudkan akuntabilitas pengelolaan keuangan. Hasil dari penelitian ini menyatakan kejelasan sasaran anggaran berpengaruh positif terhadap 
akuntabilitas pengelolaan dana desa yang dimana hasil penelitian ini memperkuat pernyataan tersebut. Hasil dari penelitian ini juga terbukti sejalan dengan penelitian sebelumnya dari Hidayat (2015), Ali (2015) serta Judarmita \& Supadmi (2017) yang menyatakan jelasnya sasaran anggaran memilik pengaruh terhadap akuntabilitas pengelolaan dari dana desa.

Kompetensi aparatur desa mempunyai nilai signifikansi yang lebih kecil dari 0,05 serta $\mathrm{t}$ hitung positif mengindikasikan $\mathrm{H}_{1}$ diterima. Dapat disimpulkan bahwa semakin berkompeten aparatur desa akan berdampak pada peningkatan akuntabilitas dari pengelolaan dana desa.

Agar pengelolaan dana desa dapat digunakan secara tepat dan dapat dipertanggung jawabkan untuk pembangunan berbagai aspek sangat diperlukan aparatur desa yang kompeten. Hasil dari uji yang telah dilakukan menyimpulkan bahwa kompetensi aparatur desa berpengaruh positif pada akuntabilitas pengelolaan dari dana desa yang dimana hasil ini memperkuat pernyataan tersebut. Hasil dari penelitian ini juga terbukti sejalan dengan penelitian sebelumnya dari Mahayani (2017) serta Julia \& Gayatri (2019) yang menyatakan kompetensi aparat desa memiliki pengaruh positif pada akuntabilitas pengelolaan dari dana desa.

Kepemimpinan mempunyai nilai signifikansi yang lebih kecil dari 0,05 serta $\mathrm{t}$ hitung positif mengindikasikan $\mathrm{H}_{1}$ diterima. Dapat disimpulkan jika kepemimpinan di pemerintah desa baik, maka akuntabilitas pengelolaan dari dana desa akan meningkat.

Akuntabilitas dari pengelolaan dana desa dapat terwujud dengan adanya peran dari kepala desa . Kepemimpinan yang baik juga menimbulkan semangat kerja yang baik dalam wilayah pemerintahan desa. Hasil dari uji yang telah dilakukan menyimpulkan bahwa kepemimpinan berpengaruh positif terhadap akuntabilitas pengelolaan dana desa yang dimana hasil ini memperkuat pernyataan tersebut. Hasil dari penelitian ini juga terbukti sejalan dengan penelitian sebelumnya dari Bagus et al (2013), Ratu (2017), serta Julia \& Gayatri (2019) yang menyatakan kepemimpinan memiliki pengaruh yang positif terhadap akuntabilitas pengelolaan dari dana desa.

\section{SIMPULAN}

Hasil dari penelitian ini mendukung teori agensi serta mendukung teori peran dan penelitian ini dapa digunakan sebagai bahan evalusai pemerintah desa untuk mecapai akuntabilitas pengelolaan keuangan desa.

Kejelasan sasaran anggaran, kompetensi aparatur desa, serta kepemimpinan memiliki pengaruh positif terhadap akuntabilitas pengelolaan dari dana desa, hal ini berarti jika ketiga faktor tersebut meningkat maka akuntabilitas pengelolaan dari dana desa akan ikut meningkat.

Sebaiknya aparatur desa mengetahui lebih jelas kebutuhan dari masyarakat desa, meningkatkan kompetensi yang dimiliki dan kepemimpinan pemimpin desa sebaiknya ditingkatkan. Kepada peneliti selanjutnya disarankan agar memperluas lokasi penelitian agar hasil yang didapat lebih baik. 


\section{REFERENSI}

Ali, Z. (2015). Kejelasan Sasaran Anggaran, Pengendalian Akuntansi, Sistem Pelaporan Dan Akuntabilitas Kinerja Instansi Pemerintah Pada Inspektorat Jenderal Kementerian Agama RI. Jurnal Riset Akuntansi Dan Perpajakan JRAP, 2(1), 89-96.

Amalia, R. 2017. Pengaruh Transparansi, Akuntabilitas Dan Partisipasi Masyarakat Dalam Pengelolaan Keuangan Desa Pada Pembangunan Desa. Anto,R. P. dan Amir, M. 2017. Competence of Village Apparatus In Management of Village Funds in North Konawe Regency-Indo. IOSR Journal of Business and Management Ver. VII, 19(11), hal. 2319-7668.

Ash-shidiqq, Ellectrananda Anugerah. Wibisono, Hindrawan. 2018. Akuntabilitas Pengelolaan Dana Desa Sebagai Upaya Pencegahan Korupsi Pengelolaan Dana Desa. Volume 4 Nomor 1 : 110-13. Seminar Nasional Hukum Universitas Negeri Semarang.

Aucoin, P., \& Heintman, R. 2000. The Dialectics of Accountability for Performance in Public Management Reform. International Review of Administrative Sciences, 66(1). 45-55.

Artha, I. M. A. S, \& Rasmini, N. K. (2019). Pengaruh Kejelasan Sasaran Anggaran, Sistem Pelaporan dan Partisipasi Masyarakat Pada Akuntabilitas Pengelolaan Dana Desa. E-Jurnal Akuntansi Universitas Udayana, 26(1), 709-735.

Aziz, Nyimas Latifah Letty. 2016. Otonomi Desa Dan Efektivitas Dana Desa. Jurnal Penelitian Politik, 13(2), hal.193-211.

Azmy, A. 2015. Pengembangan Kompetensi Sumber Daya Manusia Untuk Mencapai Career Ready Profesional Di Universitas Tanri Abeng. Binus Business Review, 6(2), hal. 220-232.

Bagus, I., Dharmanegara, A., \& Sudarma, M. (2013). Mediation Of Tri Hita Karana Organizational Culture In Effect Of Spiritual Intelligence And Asta Brata Leadership On Employee Performance. Interdisciplinary Journal Of Contemporary Research In Business, 2(11), 475-486.

Barton, A. 2006. Public Sector Accountability and Commercial-in-confidence Outsourcing Contracts. Accounting, Auditing, \& Accountability Journal, $19,2,256-271$.

Boučková, M. 2015. Management Accounting and agency Theory. Procedia Economics and Finance, 25(15), 5-13.

Cahyono, Dwi. 2008. “Persepsi Ketidakpastian Lingkungan, Ambiguitas Peran, dan Konflik Peran Sebagai Mediasi antara Program Mentoring dengan Kepuasan Kerja, Prestasi Kerja dan Niat Ingin Pindah." Disertasi tidak dipublikasikan. Universitas Diponegoro Semarang.

Darmadi, Iqbal Nul Hakim dan Zulaikha.2013. Analisis Faktor yang Mempengaruhi Manajemen Pajak dengan Indikator Tarif Pajak Efektif (Studi Empiris pada Perusahaan Manufaktur yang Terdaftar di BEI pada tahun 2011-2013). Diponegoro Journal of Accounting. Vol. 2, No. 4, Hal 1-12.

Eka, S., Fathoni, M., \& Rengu, S. P. (2015). Pengaruh Kompetensi Terhadap Kinerja Pegawai : 61-78. Dalam Pembangunan Fisik Desa (Studi di Desa 
Denok Kecamatan Lumajang Kabupaten Lumajang). Jurnal Administrasi Publik (JAP), 1(3), 139-336.

Fatmawati, A. Handajani., Lilik dan Dwi Putra Buana Sakti. 2018. Village Funds Accountability and Misuse Prevention. Indonesian Jaournal of Business Finance and Accounting, 1(36), hal.45-55.

Fauzan, Reyhan Hady. 2017. Pengaruh Kejelasan Sasaran Anggaran, Pengendalian Akuntansi, Sistem Pelaporan Dan Penerapan Akuntabilitas Keuangan Terhadap Akuntabilitas Kinerja Instansi Pemerintah (AKIP). Vol. 4 No. 1. JOM Fekon.

Ghozali, Imam. 2011. Aplikasi Analisis Multivariate dengan Program IBM SPSS 19. Semarang: Badan Penerbit Universitas Diponegoro.

Hanafie, Haniah., Nugraha, Agus., dan Masrul, H. (2019). Akuntabilitas Dana Desa (Kajian Tentang Akuntabilitas Dana Desa Di Kecamatan Masalembu, Kabupaten Sumenep). Jurnal Ilmu Pemerintahan:Kajian Ilmu Pemerintahan Dan Politik Daerah, 4(1), 39-46.

Hidayat, T. (2015). Pengaruh Kejelasan Sasaran Anggaran, Struktur Desentralisasi Dan Locus Of Control Pada Kinerja Manajerial. E-Jurnal UIN Syarif Hidayatullah Jakarta, 2(8), 148-161.

Homayoun, Saed., Homayoun, S. 2015. Agency Theory and Corprate Governance. Internasiona Business Management, 9 (5), hal. 805-815.

Indonesia Coruption Watch. www.tribunnews.com.

Irianto,Bambang Setyobudi et al.(2017). The Influence of Profitability, Leverage, Firm

Size and Capital Intensity Towards Tax Avoidance. International Journal of Accounting and Taxation. Vol. 5, No. 2, pp. 33-41. ISSN: 2372-4978 (Print), 2372-4986.

Jensen dan Meckling (1976).The Theory of The Firm:Manajerial Behaviour,Agency Cost,Ownership Structure. Journal of Financial and Economic,3:305-360. North-Holland.

Judarmita, I. N., \& Supadmi, N. L. (2017). Pengaruh Kejelasan Sasaran Anggaran, Sistem Pelaporan dan Audit Kinerja Terhadap Akuntabilitas Pengelolaan Dana Desa. E-Jurnal Akuntansi Universitas Udayana., 21(3), 1719-1746.

Julia P. D, N. K. A., \& Gayatri. (2019). Faktor-Faktor Yang Berpengaruh Pada Akuntabilitas Pengelolaan Dana Desa. E-Jurnal Akuntansi Universitas Udayana, 26(2), 1269-1298.

Kementrian Keuangan. (2017). Buku Pintar Dana Desa Desa.

Kolibácová, G. (2014). The relationship between competency and performance. Acta Universitatis Agriculturae et Silviculturae Mendelianae Brunensis, 6(24), 1315-1327.

Mahayani, N. L. A. (2017). Prosocial Behavior Dan Persepsi Akuntabilitas Pengelolaan Dana Desa Dalam Konteks Budaya Tri Hita Karana. Jurnal Ilmiah Akuntansi Dan Bisnin Universitas Udayana, 129-144.

Nurjaman, R. 2015. Dinamaka dan Problematika Implementasi UU Desa: Pembelajaran dari Daerah di Jawa Barat. Jurnal Desentralisasi. 13(1).

Panda, B., \& Leepsa, N. M. (2017). Agency theory: Review of Theory and Evidence on Problems and Perspectives. Indian Journal of Corporate Governance, 10 (1), 74-95. 
Pasal 4 ayat (3) UU No 15 Tahun 2004 Tentang Pemeriksaan Pengelolaan dan Tanggung Jawab Keuangan Negara.

Pepper, A., \& Gore, J. (2015). Behavioral agency theory: new foundations for theorizing about executive compensation. Department of Management, London School of Economics and Political Science, Houghton Street.

Peraturan Menteri Dalam Negeri No. 113 Tahun 2014 tentang Pengelolaan Keuangan Desa.

Peraturan Menteri Desa No. 2 Tahun 2015 tentang Pedoman Musyawarah Desa.

Peraturan Pemerintah No. 72 Tahun 2005 tentang Pemerintah Desa Tentang Perubahan Atas Peraturan Pemerintah Nomor 43 Tahun 2014 tentang Peraturan Pelaksanaan Undang-Undang Nomor 6 Tahun 2014 tentang Desa

Peraturan Pemerintah Nomor 71 Tahun 2010 Tentang Standar Akuntansi Pemerintah

Ratu, N. I. H. (2017). Kecerdasan Spiritual Memoderasi Gaya Kepemimpinan dan Budaya Organisasi pada Kinerja Penyusun Laporan Akuntabilitas Kinerja Instansi Pemerintah. E-Jurnal Akuntansi Universitas Udayana.

Robbin, Stephen P. dan Timothy A. Judge.2015. Perilaku Organisasi. Jakarta: Salemba Barat.

Sarwono, S.W. 2002. "Teori-teori Psikologi Sosial." PT Raja Grafindo Persada.

Scott, C. 2000. Accountability in The Regulatory State. Journal of Law and Society, 27(1), 38-60. Cardiff University

Sesen, Elif. 2015. European Journal of Business and Social Science, 4(1), hal.136-143. Europeen Journal of Business and Social Sciences:Turkey

Setiana, N. D. dan Yuliani, N. L. 2017. Pengaruh Pemahaman dan Peran Perangkat Desa Terhadap Akuntabilitas Pengelolaan Dana Desa (Studi Pada Desa se-Kecamatan Mungkid). University Research Colloquium, hal. 205-120.

Shende, Suresh dan Tony Bennet. 2004. Concept Paper 2: Transparency and Accountability in Public Financial Administration. United Nations. Department of Economic and Social Affairs. Division for Public Administration and Development Management:New York.

Silva, A. (2016). What is Leadership ? Journal of Business Studies Quarterly, 8(1), 15. Keiser University

Soerjono Soekanto. Sosiologi Suatu Pengantar. Jakarta: Raja Grafmdo Persada. 2002.

Sugiyono. (2014). Metode Penelitian Pendidikan Pendekatan Kuantitatif, Kualitatif, dan R\&D. Bandung: Alfabeta

Sugiyono. 2017. Metode Penelitian Bisinis. Edisi Ketiga. Bandung: Alfabeta.

Sutrawati, Kadek. 2016. Peran Perangkat Desa dlaam Akuntabilitas Pengelolaan Dana Desa, Skripsi Sarjana Jurusan Akuntansi pada Fakultas Ekonomi dan Bisnis Universitas Halu Oleo, Kendari.

Synthia. 2017. The Effect of Human Resources Competence and Application of Regional Financial Accounting Systems on Quality of Financial Report. Vol.2.No. 1.68-

74. Journal of Applied Accounting and Taxation

Undang-Undang No. 6 Tahun 2014 Tentang Desa 
Undang-Undang Nomor 18 Tahun 2016 Tentang Anggaran Pendapatan dan Belanja Negara.

Utama, Suyana. 2009. Aplikasi Analisis Kuantitatif. Denpasar: Sastra Utama.

Yuki G. 2016. Leadership in Organization. 8th Edition. New York: Pearson.Yunita, A., \& Christianingrum, M. (2018). Measurement of Accountability Management of Village Funds. Integrated Journal of Business and Economics, 2(1), 99-103 